\title{
Stat3/Oct-4/c-Myc signal circuit for regulating stemness-mediated doxorubicin resistance of triple-negative breast cancer cells and inhibitory effects of WP1066
}

\author{
CONG-CONG CHENG ${ }^{1,2^{*}}$, LI-HONG SHI ${ }^{1,3^{*}}$, XUE-JIAN WANG ${ }^{1,3}$, SHU-XIAO WANG $^{3}$, XIAO-QING WAN ${ }^{1}$, \\ SHU-RONG LIU ${ }^{1,2}$, YI-FEI WANG ${ }^{1,2}$, ZHONG LU $^{1,2}$, LI-HUA WANG ${ }^{1,2}$ and YI DING ${ }^{1}$ \\ ${ }^{1}$ Laboratory of Molecular Oncology; ${ }^{2}$ Affiliated Hospital; ${ }^{3}$ Department of Pharmacology, \\ Weifang Medical College, Weifang, Shandong 261053, P.R. China
}

Received January 22, 2018; Accepted April 11, 2018

DOI: 10.3892/ijo.2018.4399

\begin{abstract}
Doxorubicin (Dox) is widely used in the treatment of triple-negative breast cancer cells (TNBCs), however resistance limits its effectiveness. Cancer stem cells (CSCs) are associated with Dox resistance in MCF-7 estrogen receptor positive breast cancer cells. Signal transducer and activator of transcription 3 (Stat3) may functionally shift non-CSCs towards CSCs. However, whether Stat 3 drives the formation of CSCs during the development of resistance in TNBC, and whether a Stat 3 inhibitor reverses CSC-mediated Dox resistance, remains to be elucidated. In the present study, human MDA-MB-468 and murine 4T1 mammary carcinoma cell lines with the typical characteristics of TNBCs, were compared with estrogen receptor-positive MCF-7 cells as a model system. The MTT assay was used to detect cytotoxicity of Dox. In addition, the expression levels of CSC-specific markers and transcriptional factors were measured by western blotting, immunofluorescence staining and flow cytometry. The mammosphere formation assay was used to detect stem cell activity. Under long-term continuous treatment with Dox at a low concentration, TNBC cultures not only exhibited a drug-resistant phenotype, but also showed CSC properties. These Dox-resistant TNBC cells showed activation of Stat3 and high expression levels of pluripotency transcription factors octamer-binding transcription factor-4 (Oct-4) and c-Myc, which was different from the high expression of superoxide dismutase 2 (Sox2) in Dox-resistant MCF-7 cells. WP1066 inhibited the phosphorylation of Stat3, and decreased the
\end{abstract}

Correspondence to: Dr Yi Ding or Dr Li-Hua Wang, Laboratory of Molecular Oncology, Weifang Medical College, 7166 Baotong West Street, Weifang, Shandong 261053, P.R. China

E-mail: dingy@wfmc.edu.cn

E-mail: wanglihua@wfmc.edu.cn

${ }^{*}$ Contributed equally

Key words: signal transducer and activator of transcription 3, WP1066, cancer stem cells, triple-negative breast cancer cells, doxorubicin, drug resistance expression of Oct- 4 and c-Myc, leading to a reduction in the CD44-positive cell population, and restoring the sensitivity of the cells to Dox. Taken together, a novel signal circuit of Stat3/Oct-4/c-Myc was identified for regulating stemnessmediated Dox resistance in TNBC. The Stat 3 inhibitor WP1066 was able to overcome the resistance to Dox through decreasing the enrichment of CSCs, highlighting the therapeutic potential of WP1066 as a novel sensitizer of Dox-resistant TNBC.

\section{Introduction}

Triple-negative breast cancer (TNBC), which is negative for estrogen receptor (ER), progesterone receptor and human epidermal growth factor 2, is an aggressive subtype of breast cancer that has significant morbidity and mortality rates (1-5). Doxorubicin (Dox), a topoisomerase II inhibitor, is usually applied for the treatment of TNBC $(1,2,6,7)$. However, the effectiveness is restricted by the development of resistance (7). Drug resistance was originally attributed to drug efflux mediated by adenosine triphosphate-binding cassette transporter $(8,9)$. Increasing evidence has indicated the existence of cancer stem cells (CSCs) in breast cancer, and these CSCs are involved in the process of cancer initiation, metastasis, recurrence and therapeutic resistance $(3,6,10-22)$. CSCs have cancer-initiating capability and metastatic potential (4,23-27). CD44 is a cell surface receptor for the extracellular matrix protein hyaluronan. CSCs expressing CD44 are considered to be responsible for adhesion, invasion, metastasis and the acquisition of resistance to apoptosis $(6,12,25,28-33)$. ATP-binding cassette subfamily $\mathrm{G}$ member 2 (ABCG2) is overexpressed in several types of tumor and tumor cell lines $(5,10,17,34-38)$. ABCG2 is not only associated with MDR, but may also function as a breast cancer stem cell marker $(20,34,35,37,38)$. Although CD133 was initially described as a specific marker of human hematopoietic stem cells $(13,14,17,34,39,40)$, CD133 has been used as the primary marker of putative CSCs and has been reported to be the most reproducible marker of breast CSCs (BCSCs) $(14,24,27,39,41)$. Therefore, cells expressing high levels of cell surface markers, including CD44, ABCG2 and CD133, have stem-like activities $(10,17,24)$. As the majority of information on CSCs in breast cancer cells has 
come from studies on the MCF-7/ADR cell line, originated from ER-positive MCF-7 cells $(2,14,16)$, whether resistance of TNBCs to Dox is associated with the development of CSCs and, if so, the molecular characteristic phenotype of TNBC-derived CSCs remain to be elucidated.

The development and enrichment of CSCs may rely on the orchestration of multiple critical transcription factors. Pluripotent transcription factors contribute to the reprogramming of somatic cells into an embryonic stem cell (ESC)-like state $(3,18)$. CSCs express members of the ESC core pluripotency complex, including octamer-binding transcription factor-4 (Oct4), superoxide dismutase 2 (Sox2) and Nanog, which are positively correlated with the development of CSCs $(3,18,24,42-44)$. Furthermore, the Myc oncogene also forms a complex on its own (Myc-complex) to mediate CSCs (45-47). In addition to the overexpression of the above specific pluripotency transcriptional factors, signal transducer and activator of transcription 3 (Stat3) is important for mammosphere formation and the CSC process in breast cancer $(3,15,46,48,49)$. The activation of Stat 3 shifts non-CSC dynamics towards CSCs and regulates its downstream genes $(3,18,50)$, in addition to other signaling molecules, which are important in tumorigenesis. It has been reported that the inhibition of Stat 3 increased Dox sensitivity in the MDA-MB-231 human breast cancer cell line. Therefore, it was hypothesized that Stat 3 inhibition may decrease the enrichment of CSCs during the induction of Dox resistance in TNBC cells.

In the present study, human MDA-MB-468 and murine 4T1 mammary carcinoma cell lines with the typical characteristics of TNBC were used as a model system to investigate the effects of the Stat 3 signaling pathway and its inhibitor, WP1066, on the enrichment of CSCs and development of Dox resistance in breast cancer cells. TNBC cultures under prolonged selection with Dox at a low concentration exhibited a drug-resistant phenotype and had CSC properties with high expression levels of CD44, CD133 and ABCG2; this was regulated by Stat3-driven stemness through upregulating the expression of Oct- 4 and c-Myc. This indicated a Stat $3 /$ Oct-4/c-Myc signaling circuit for the modulation of CSC-mediated Dox resistance in TNBC. The data provided direct evidence that WP1066 inhibited the Stat3-mediated enrichment of CSCs, in turn overcoming the resistance to Dox.

\section{Materials and methods}

Reagents. Dox (Solarbio, Beijing, China) was dissolved in sterile water in a $10 \mathrm{mM}$ stock solution. WP1066 (Selleckchem, Shanghai, China) and 3-(4,5-dimethyl-2-thiazolyl)-2,5-diphenyl-2-H-tetrazolium bromide (MTT; Solarbio) were lysed in DMSO (Beijing Solarbio Science \& Technology Co., Ltd., Beijing, China) in $50 \mathrm{mM}$ and $5 \mathrm{mg} / \mathrm{ml}$ stock solutions, respectively.

Cell lines and culture. The human MDA-MB-468 cell line, mouse breast cancer 4T1 cell line and human MCF-7 cell line were obtained from American Type Culture Collection (Manassas, VA, USA). The cells were cultured in RPMI-1640 supplemented with 10\% FBS (both from HyClone; GE Healthcare Life Sciences, Logan, UT, USA) and $1 \%$ penicillin/streptomycin (Beijing Solarbio Science \& Technology Co., Ltd.). All cultures were maintained at $37^{\circ} \mathrm{C}$ in a humidified $5 \% \mathrm{CO}_{2}$ incubator. The MCF-7/Epr human epirubicin-resistant breast cancer cell line was obtained from Shanghai Bogoo Biotechnology (Shanghai, China), which was originally selected with $1,000 \mathrm{ng} / \mathrm{ml}$ epirubicin.

Mammosphere formation assay. Tumorsphere culture was performed in low attachment dishes (Corning Incorporated, Corning, NY, USA). The cells were seeded at a density of 8,000 cells per well into a 6-well plate supplemented with $1 \mathrm{X}$ B27 and 2X N-2 (both from Gibco; Thermo Fisher Scientific, Inc., Waltham, MA, USA), $20 \mathrm{ng} / \mathrm{ml}$ EGF, $20 \mathrm{ng} / \mathrm{ml} \mathrm{IGF,} 10 \mathrm{ng} / \mathrm{ml}$ FGF-basic (all from PeproTech, Inc., Rocky Hill, NJ, USA) and $5 \mu \mathrm{g} / \mathrm{ml}$ heparin (Beijing Solarbio Science \& Technology Co., Ltd.). The cells were maintained at $37^{\circ} \mathrm{C}$ in a humidified incubator containing $5 \% \mathrm{CO}_{2}$. Following 7 days of culture, the wells were examined under an inverted microscope at $\mathrm{x} 400$ magnification.

Immunofluorescent staining. The Dox-resistant tumor cells and parental tumor cells were harvested by cytospin, respectively, and fixed in $4 \%$ paraformaldehyde for $10 \mathrm{~min}$. The slides were washed three times in 1X PBS and, using goat sera (Wuhan Boster Biological Technology, Ltd., Wuhan, China), the cells were blocked for $1 \mathrm{~h}$. The cells were incubated with CD133 (1:500 dilution, cat. no. 18470-I-AP; ProteinTech Group, Inc., Chicago, IL, USA) and ABCG2 (1:500 dilution, cat. no. ab130244; Abcam, Cambridge, MA, USA) primary antibodies at $4^{\circ} \mathrm{C}$. Following a wash in PBS, the cells were incubated with immunoglobulin $\mathrm{G} /$ tetramethylrhodamine goat anti-rabbit antibody (1:200 dilution, cat. no. ZF0316; OriGene Technologies, Inc., Beijing, China) for $1 \mathrm{~h}$ at $4^{\circ} \mathrm{C}$. The cells were then washed with PBS, stained with DAPI for $10 \mathrm{~min}$, washed, and covered with mounting medium. Immunofluorescent staining was observed and images were captured.

Western blot analysis. Total protein was extracted from the Dox-resistant TNBC cells and parental cells, respectively. Briefly, the cells were lysed with RIPA lysis buffer combined with PMSF (both from Beijing Solarbio Science \& Technology Co., Ltd.) and then centrifuged at $12.000 \mathrm{x} \mathrm{g}$ for $15 \mathrm{~min}$ at $4^{\circ} \mathrm{C}$. The supernatants were collected for western blot analysis and protein concentration was determined using the BCA method (CWBio, Beijing, China). Total protein $(25 \mu \mathrm{g})$ was separated by $10 \%$ sodium dodecyl sulfate-polyacrylamide gel electrophoresis and transferred onto a polyvinylidene fluoride membrane (EMD Millipore, Billerica, MA, USA). The membranes were blocked with 5\% non-fat dry milk in TBST for $1 \mathrm{~h}$ and then blotted overnight at $4^{\circ} \mathrm{C}$ with the following primary antibodies: Mouse monoclonal $\beta$-actin (1:3,500 dilution, cat. no. 66009-1-Ig; PeproTech, Inc.); mouse monoclonal Stat3 (1:1,000 dilution, cat. no. 9139s); mouse monoclonal phosphorylated (p)-Stat3 (1:1,000 dilution, cat. no. 4113s) (both from Cell Signaling Technology, Inc., Danvers, MA, USA); rabbit monoclonal Oct-4 (1:1,000 dilution, cat. no. ab200834); rabbit monoclonal c-Myc (1:5,000 dilution, cat. no. ab32072); rabbit monoclonal Sox2 (1:1,000 dilution, cat. no. ab92494); mouse monoclonal ABCG2 (1:1,000 dilution, cat. no. ab130244) (all from Abcam) and rabbit polyclonal CD133 (1:1,000 dilution, cat. no. 18470-1-AP; PeproTech, Inc.) 
A

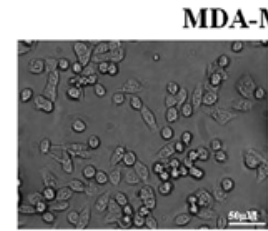

Ctrl

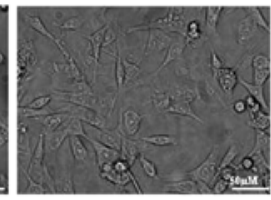

Doxorubicin
C

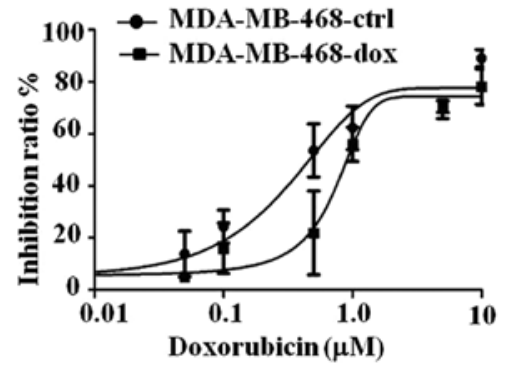

E

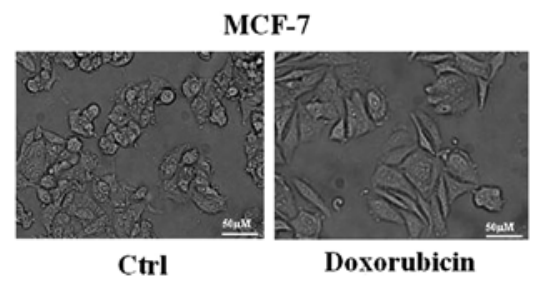

B

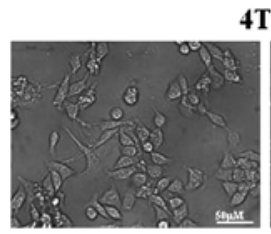

Ctrl
$4 \mathrm{T1}$

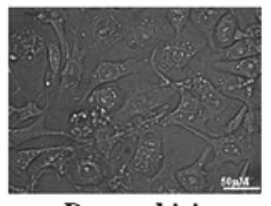

Doxorubicin

D

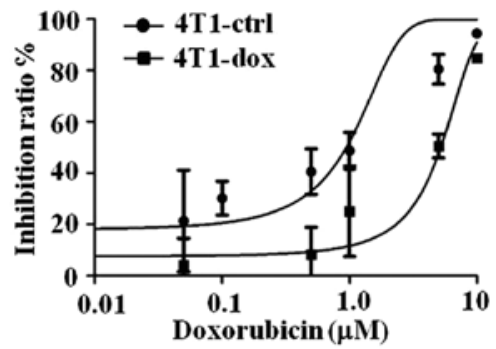

F

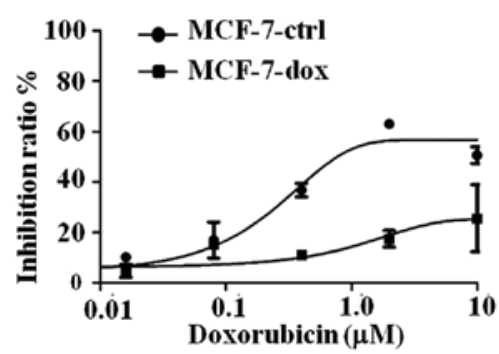

Figure 1. Establishment of Dox-resistant of triple-negative breast cancer cells by long-term exposure of Dox at a low concentration. (A) Morphological images of parental MDA-MB-468 cells and MDA-MB-468-Dox. (B) Morphological images of parental 4T1 cells and 4T1-DOX cells. (C) Comparison of cytotoxicity between parental MDA-MB-468 cells and MDA-MB-468-DOX cells against Dox, examined by MTT assay. (D) Comparison of cytotoxicity between parental 4T1 cells and 4T1-DOX cells against Dox, examined by MTT assay. (E) Morphological images of parental MCF-7 cells and MCF-7-DOX cells. (F) Comparison of cytotoxicity between parental MCF-7 cells and MCF-7-DOX cells against Dox examined by MTT assay. The results are representative of four independent experiments. Dox, doxorubicin; MTT, 3-(4,5-dimethyl-2-thiazolyl)-2,5-diphenyl-2-H-tetrazolium bromide; Ctrl, control.

antibodies. The membranes were then blotted for $1 \mathrm{~h}$ at room temperature with anti-mouse (1:5,000 dilution, cat. no. A0216) and anti-rabbit (1:3,500 dilution, cat. no. A0208) secondary antibodies (both from Beyotime Institute of Biotechnology, Shanghai, China). The signal was detected using enhanced chemiluminescence (Immobilon Western Chemiluminescent Horseradish Peroxidase Substrate, cat. no. WBKLS0100; EMD Millipore) and recorded on X-ray film.

Flow cytometry. The dissociated MDA-MB-468-Dox cells, 4T1-Dox cells and their parental cells were counted and transferred into a tube, respectively. The cells were washed and resuspended in PBS at a concentration of $10 \% \mathrm{ml}$. The cell suspensions were incubated with PE-rat anti-mouse CD44 antibody, which also cross-reacts with human cells (1:100 dilution, cat. no. 553134; BD Biosciences, Franklin Lakes, NJ, USA) for $30 \mathrm{~min}$ at room temperature. Following washing with PBS, the samples were analyzed using a FACSCalibur. Isotype-matched PE-rat IgG2b (1:100 dilution, cat. no. 553989; BD Biosciences) served as negative control.

MTT assay. The MDA-MB-468-Dox cells, 4T1-Dox cells, MCF-7-Dox cells and their parental cells were seeded into 96-well plates at a density of $\times 10^{3}$ cells/well in RPMI-1640 medium supplemented with $10 \%$ FBS. The cells were treated with Dox at various concentrations $(0,0.05,0.1,0.5,1,5$ and $10 \mu \mathrm{M})$ for $48 \mathrm{~h}$ at $37^{\circ} \mathrm{C}$. MTT solution $(5 \mathrm{mg} / \mathrm{ml})$ was added to the plates $(20 \mu 1$ per well). The plates were incubated at $37^{\circ} \mathrm{C}$ for an additional $4 \mathrm{~h}$. The supernatant was discarded, and $150 \mu 1$ DMSO was added to each well. The plates were thoroughly mixed and read at $570 \mathrm{~nm}$ on a microplate reader.

Statistical analysis. Each experiment was performed at least three times. Data are presented as the mean \pm standard deviation. A one-way analysis of variance was performed for comparisons between two subgroups, and the Fisher's least significant difference post hoc test was used for determination of the significance among the means of multiple groups using SPSS version 17.0 software (SPSS, Inc., Chicago, IL, USA). $\mathrm{P}<0.05$ was considered to indicate a statistically significant difference.

\section{Results}

Establishment of Dox-resistant TNBC cells by long-term exposure to Dox at a low concentration. Dox has been documented to induce the resistance of ER-positive MCF-7 breast cancer cells by exposure to a high dose of Dox. To establish Dox-resistant TNBC cell lines, human MDA-MB-468 and murine 4T1 cells were treated with a long-term low dose of Dox. Based on the dose-dependent curve of Dox, the concentration of $0.05 \mu \mathrm{M}$ Dox was used to stimulate MDA-MB-468 cells and $0.1 \mu \mathrm{M}$ of Dox was used to stimulate the 4T1 cells. Following continuous treatment with Dox for 4 weeks, morphological differences were observed between the parental cells and the Dox-resistant TNBC cells (Fig. 1A and B). These 
Dox-treated cells were termed MDA-MB-468-Dox cells and 4T1-Dox cells, and were banked for further investigations.

The cytotoxicity of Dox in the Dox-resistant cell lines and their parental cells was examined using an MTT assay. The dose-dependent effects of Dox in the above two pairs of cell lines are shown in Fig. 1C and D. Compared with the parental cancer cells, the cytotoxicity of Dox towards the Dox-resistant TNBC cells was significantly decreased. The $\mathrm{EC}_{50}$ of Dox in the parental MDA-MB-468 cells was $0.47 \mu \mathrm{M}$, whereas the $\mathrm{EC}_{50}$ of the MDA-MB-468-Dox was increased to $0.92 \mu \mathrm{M}$ $\left(\mathrm{P}<0.05\right.$; Fig. 1C). Similarly, the $\mathrm{EC}_{50}$ of the 4T1-Dox cells was significantly increased from 0.98 to $5.37 \mu \mathrm{M}$ ( $\mathrm{P}<0.05$; Fig. 1D). These data suggested that the sensitivity of TNBC cells against Dox was significantly decreased by long-term exposure with Dox at a low concentration.

To compare Dox resistance in TNBC cells to ER-positive cells, a human epirubicin-resistant breast cancer cell line MCF-7/Epr was induced into a Dox-resistant cell line, termed MCF-7-Dox, by prolonged exposure to $0.9 \mu \mathrm{M}$ Dox for 4 weeks (Fig. 1E). The MTT assay demonstrated that the ER-positive MCF-7-Dox cells, compared with the original cell line, was less sensitive to Dox (Fig. 1F). The results confirmed the results of a previous report that a high dose of Dox is required for maintenance of the drug-resistant phenotype of MCF-7/ADR cells (5).

Dox-resistant TNBC cells exhibit characteristics of stem-like cells. As cells that are intrinsically resistant to chemotherapy may have CSC characteristics $(8,21,22,24,28,36)$, the present study examined whether MDA-MB-468-Dox and 4T1-Dox cells have properties of the CSC phenotype through examining specific CSC markers expressed on the surface of the Dox-resistant cells. The Dox-resistant breast cancer cells were analyzed for the expression of the CSC surface marker CD44 by flow cytometry. As shown in Fig. 2A-C, the expression of CD44 in the Dox-resistant TNBC cells was higher than that in the parental cells. As expected, exposure to Dox increased the expression of CD44 in MCF-7-Dox cells, which was consistent with the observation by Calcagno et al (5).

The expression levels of CD133 and ABCG2 in the MDA-MB-468-Dox, 4T1-Dox and MCF-7-Dox cells were observed by western blot analysis. The levels of CD133 and ABCG2 were markedly higher in the MDA-MB-468-Dox and 4T1-Dox cells, compared with those in their parental cells (Fig. 2D). The high expression levels of CD133 and ABCG2 in 4T1-Dox cells were also observed by immunofluorescence (Fig. 2E). In the MCF-7-Dox cells, continuous stimulation with Dox upregulated the expression of CD133, but did not affect the expression of ABCG2. These data suggested that the Dox-resistant TNBC cells exhibited typical CSC molecular properties with high expression levels of CD44/CD133/ABCG2, which differed from the CSC biomarker characteristics of MCF-7-Dox cells.

The present study also performed mammosphere formation assays to evaluate the sphere-forming ability of Dox-resistant 4T1 cells. As shown in Fig. 2F, the volume of the sphere formed by Dox-resistant 4T1 cells was larger than that of the parental 4T1 cells. The numbers of mammospheres of the Dox-resistant 4T1 cells were also higher compared with those of the control 4T1 cells. These data obtained from the expression of surface molecular markers and mammosphere formation capacity indicated that continuous stimulation with Dox at a low dose induced the enrichment of CSCs in TNBC cells.

Expression levels of Oct-4 and c-Myc are increased in Dox-resistant cells. The high expression levels of pluripotent transcription factors, including Oct-4, Sox 2 and c-Myc, has been reported in CSCs, which may promote stem cell selfrenewal and differentiation $(3,18,24,26)$. To clarify the roles of pluripotent transcription factors in regulating the enrichment of CSCs induced by Dox, the present study examined the expression of these genes in BCSCs induced by Dox. As shown in Fig. 3A, compared with their parental cancer cells, the expression levels of Oct- 4 and c-Myc were increased in the Dox-resistant TNBC cells, whereas the expression of Sox 2 was not altered significantly. However, the expression of Sox 2 in MCF-7-Dox cells was increased. These results indicated that the upregulated expression of Sox 2 may be a major factor in the CSC activities of MCF-7-Dox cells. Notably, Dox induced the expression of Oct-4 and c-Myc, but did not affect the expression of Sox 2 to promote the CSC enrichment in the TNBC cells.

Activation of Stat3 is involved in CSC enrichment induced by Dox. In addition to specific pluripotency transcriptional factors, Stat 3 is also reported to be a key mediator for mammosphere formation and the CSC process in breast cancer $(3,15,18,49,50)$. To investigate whether Stat 3 is involved in CSC enrichment induced by Dox, the present study examined the expression and activation of Stat3. As shown in Fig. 3B, the phosphorylation of Stat 3 was elevated in Dox-resistant breast cancer cells, whereas there was no significant change in the total expression of Stat3. This finding suggested that the activation of Stat3 was also involved in the regulation of CSC formation induced by Dox in breast cancer cells.

Inactivation of Stat3 by WP1066 reverses Dox resistance of TNBC cells by downregulating the expression of $c-M y c$ and Oct-4 and reducing CSC enrichment. From the above data, it was observed that the pluripotency transcriptional factors Oct-4 and c-Myc, and the activation of Stat3 were involved in the Dox-induced CSC enrichment in TNBC. The CSCs transcriptional factor c-Myc is a recognized transcriptional target of Stat 3 in embryonic stem cells and hematopoietic stem cells $(18,47)$. Oct-4 also acts as a downstream factor of Stat3 during mammosphere culture (3). Therefore, the Stat 3 inhibitor WP1066 (51-56) was used to examine whether the inactivation of Stat 3 affects the interaction between Stat 3 and Oct-4/c-Myc in the process of Dox-induced CSC enrichment. Treatment with WP1066 $(1.25 \mu \mathrm{M})$ not only decreased the phosphorylation of Stat3 (Fig. 4A), but also markedly downregulated the expression of Oct-4 and c-Myc (Fig. 4A). These data suggested that continuous Dox stimulation promoted the enrichment of CSCs through the activation of Stat3, which increased the expression of pluripotency transcriptional factors Oct-4 and c-Myc.

An MTT assay was performed to evaluate whether WP1066 restored the sensitivity of MDA-MB-468-Dox and 4T1-Dox cells to Dox. Following incubation with WP1066 $(1.25 \mu \mathrm{M})$, the $\mathrm{EC}_{50}$ of MDA-MB-468-Dox cells was decreased from 0.32 to $0.14 \mu \mathrm{M}\left(\mathrm{P}<0.05\right.$; Fig. 4B). Similarly, the $\mathrm{EC}_{50}$ 

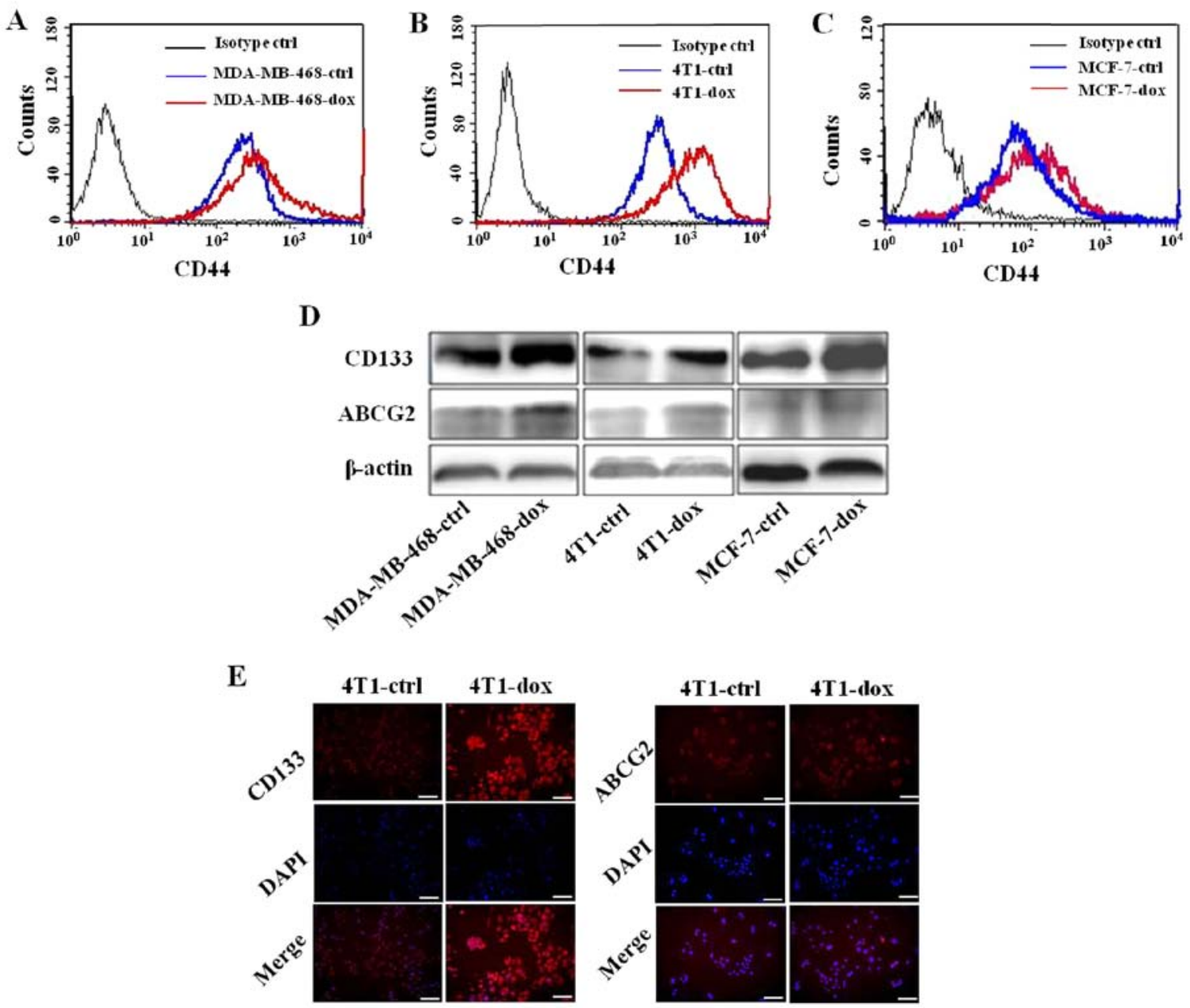

F

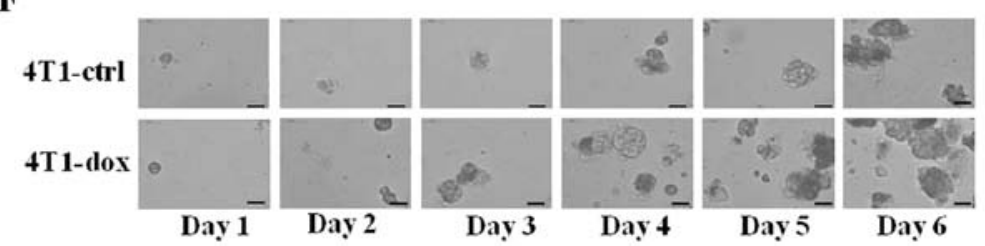

Figure 2. Dox-resistant breast cancer cells exhibit characteristics of stem-like cells. Flow cytometric analysis showed increased expression of CD44 in (A) MDA-MB-468-Dox, (B) 4T1-Dox, and (C) MCF-7-Dox cells, compared with their parental cells. (D) Western blot analysis for CD133 and ABCG2 in MDA-MB-468-Dox, 4T1-Dox and MCF-7-Dox cells, compared with their parental cells. (E) Immunofluorescence staining showed upregulated expression of CD133 (left, red) and ABCG2 (right, red) in 4T1-Dox cells, counterstained with DAPI (blue), respectively. Scale bar, $100 \mu \mathrm{m}$. The results are representative of three independent experiments. (F) Comparison of tumorsphere formation capability between 4T1-Dox and parental 4T1 cells. Scale bar, 50 $\mu \mathrm{m}$. The results are representative of four independent experiments. Dox, doxorubicin; ABCG2, ATP-binding cassette subfamily G member 2; ctrl, control.

of 4T1-Dox was decreased from 5.37 to $2.24 \mu \mathrm{M}(\mathrm{P}<0.05$; Fig. 4C). There was no significant difference in $\mathrm{EC}_{50}$ values between the WP1066 treatment group and parental MDA-MB468 or $4 \mathrm{~T} 1$ cells $(\mathrm{P}>0.05)$. These data suggested that WP1066 treatment sensitized the MDA-MB-468-Dox and 4T1-Dox cells to Dox, as demonstrated by $\mathrm{EC}_{50}$ values in WP1066-treated cells, which were similar or close to those in parental cells. In addition, following treatment with WP1066 at the concentration of $1.25 \mu \mathrm{M}$, the maximal response to Dox in the 4T1-Dox cells was lower than that in the parental 4T1 cells, indicating that this concentration of WP1066 did not completely restore the sensitivity of 4T1-Dox cells, which may be improved by increasing the dose and incubation time of WP1066.

The present study also examined whether WP1066 affects the expression of CSC markers on Dox-resistant cells.
As shown in Fig. 5A, the increased expression of CD133 and ABCG2 on the MDA-MB-468-Dox cells was reduced by WP1066 treatment (Fig. 5A). The effect of WP1066 treatment on the CD44-positive cell population was also analyzed by flow cytometry. WP1066 treatment reduced the CD44-positive cell population in the MDA-MB-468-Dox cells (Fig. 5B) and 4T1-Dox cells (Fig. 5C). Analysis of the peak channel of the flow cytometry assay showed that, under treatment with WP1066, the mean peak value of 4T1-Dox was shifted left from 731 to 533. In addition, the mean peak value of MDA-MB-468-Dox was shifted left from 896 to 771. These results indicated that the inhibition of Stat 3 downregulated the Dox-induced enrichment of the CSC population of TNBC cells, and led to reversion of TNBC cell resistance to Dox. 
A
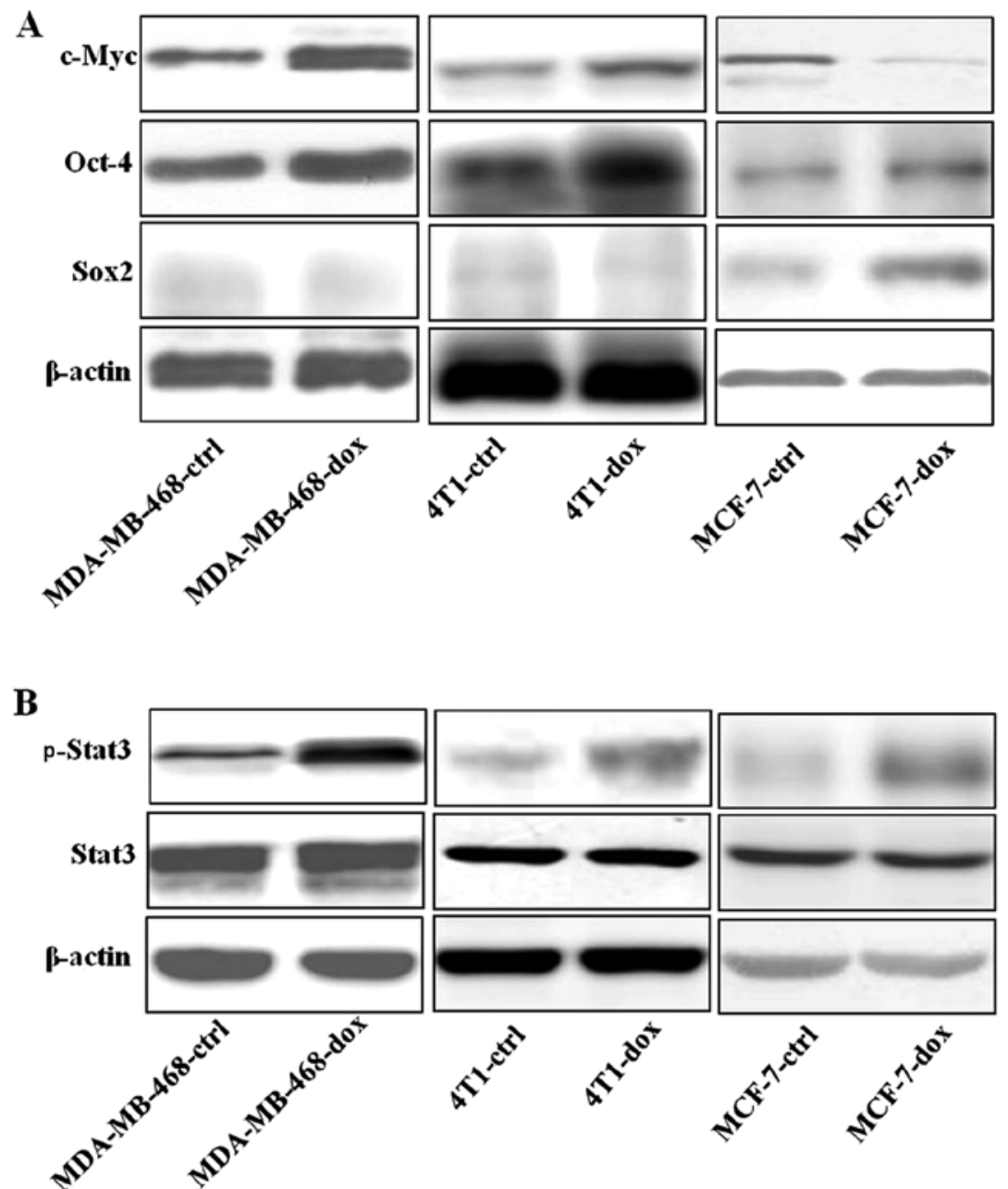

Figure 3. Changes in the expression of cancer stem cell transcriptional factors and p-Stat3 in Dox-resistant cells. (A) Western blot analysis of Sox2, Oct-4 and c-Myc in MDA-MB-468-Dox, 4T1-Dox, MCF-7-Dox cells, and their parental cells. (B) Western blot analysis of p-Stat3 and Stat3 in MDA-MB-468-Dox, 4T1-Dox, MCF-7-Dox cells, and their parental cells. The results are representative of three independent experiments. Dox, doxorubicin; Sox2, superoxide dismutase 2; Oct-4, octamer-binding transcription factor 4; Stat3, signal transducer and activator of transcription 3; p-Stat3, phosphorylated Stat3; ctrl, control.

\section{Discussion}

Dox has a broad antitumor spectrum and is widely used in the treatment of various types of cancer, including breast cancer $(1,6,7,54,55)$. Although Dox is effective in the majority of cases of primary breast cancer and almost half of the metastases at the early period of chemotherapy $(5,54,56)$, the repeated application of Dox may lead to the development of chemotherapeutic resistance $(5,7,9)$. ER-positive MCF-7/ADR cells selected by high dose of Dox have been found to overexpress $\mathrm{ABCB} 1$ protein and are widely used for investigations of the multidrug-resistant phenotype $(2,5,35)$. In the present study, it was found that, following long-term continuous exposure to Dox at a low concentration, human and mouse TNBC cell lines exhibited a drug-resistant phenotype.

The enrichment of the CSC population may cause drug resistance, leading to recurrence and metastasis of tumors with poor prognosis $(4,10,11,12,15,21-23,25,28,36,39)$. In the present study, MDA-MB-468-Dox and 4T1-Dox cells were used to investigate whether Dox induced CSC-enrichment. Using a sphere-forming assay, it was found that the low concentration of Dox $(0.1 \mu \mathrm{M})$ stimulation resulted in increased mammosphere formation capacity in 4T1-Dox cells.
In addition, increased expression levels of CSC biomarkers, including CD44, ABCG2 and CD133, were observed in the MDA-MB-468-Dox and 4T1-Dox cells, compared with those in their control parental cells. These data confirmed that exposure of TNBC cells to low dose of Dox resulted in the enrichment of BCSCs. These findings were consistent with previous observations on lung cancer cells (7). The CSCs may evade or efficiently repair DNA damage from radiation and chemotherapy, and these stem cell properties are likely to be responsible for the difficulties existing in the treatment of breast cancer $(8,16,31,32)$. Therefore, the enrichment of CSCs may contribute to the development of TNBC resistance to Dox.

Dox-induced chemoresistance in breast cancer cells may occur through the activation of Stat3 $(49,54)$. Gariboldi et al observed that the inactivation of Stat 3 by AG490 increased the sensitivity of MDA-MB-231 cells to Dox treatment (49). However, how the activated Stat 3 regulates the resistance of breast cancer cells to Dox remains to be elucidated. Pluripotent transcription factors, including Oct-4, c-Myc and Sox2, are important in the induction of CSCs through promoting CSC self-renewal $(4,18,24,26)$. The cooperation between the CSC transcriptional factors c-Myc, Oct- 4 , and the activation of Stat 3 has been considered as a mechanism in sustaining and 
A

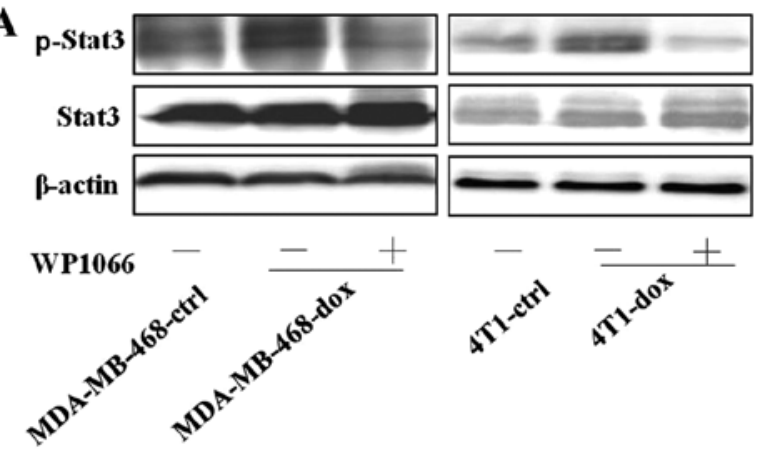

B

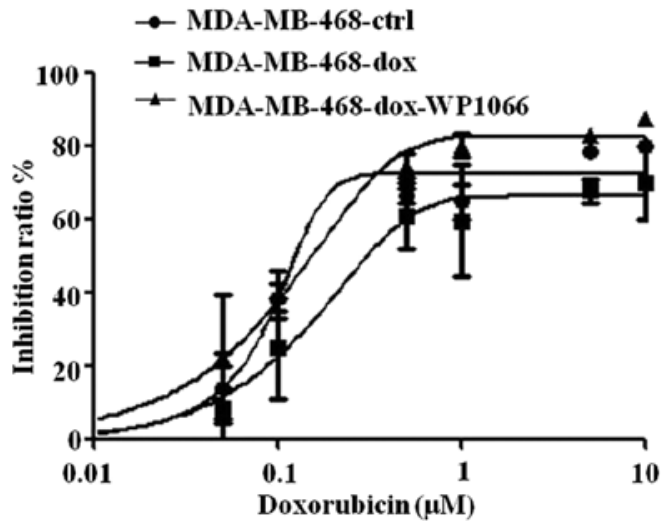

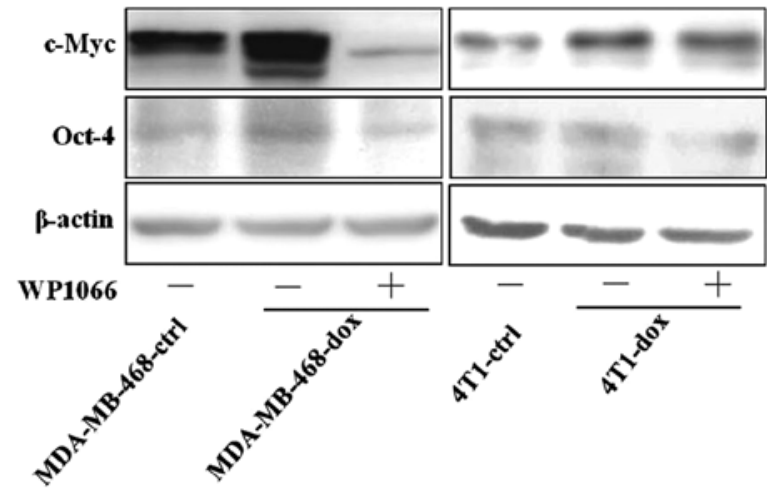

C

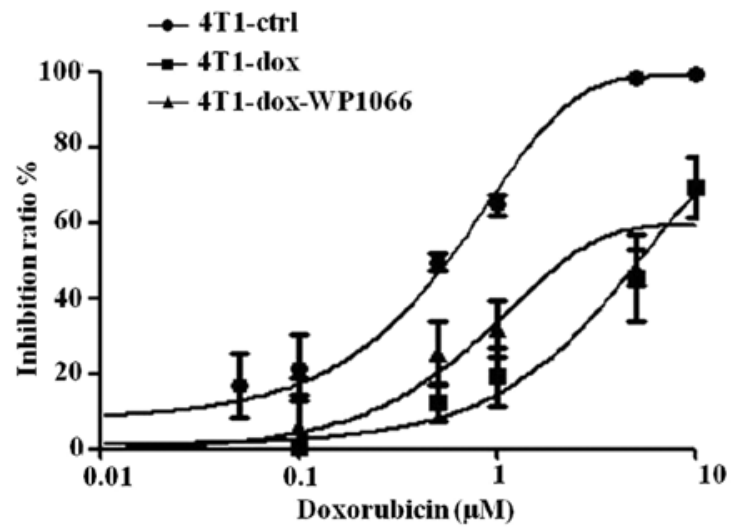

Figure 4. Inactivation of Stat3 by WP1066 restores the sensitivity of MDA-MB-468-Dox and 4T1-Dox cells to Dox. (A) Western blot analysis of Stat3, p-Stat3, c-Myc and Oct-4 in MDA-MB-468-Dox and 4T1-Dox cells treated with or without WP1066. (B) Effect of WP1066 on the sensitivity of MDA-MB-468-Dox to Dox was examined by MTT assay. (C) Effect of WP1066 on the sensitivity of 4T1-Dox to Dox was examined by MTT assay. The results are representative of three independent experiments. Dox, doxorubicin; MTT, 3-(4,5-dimethyl-2-thiazolyl)-2,5-diphenyl-2-H-tetrazolium bromide; ctrl, control.
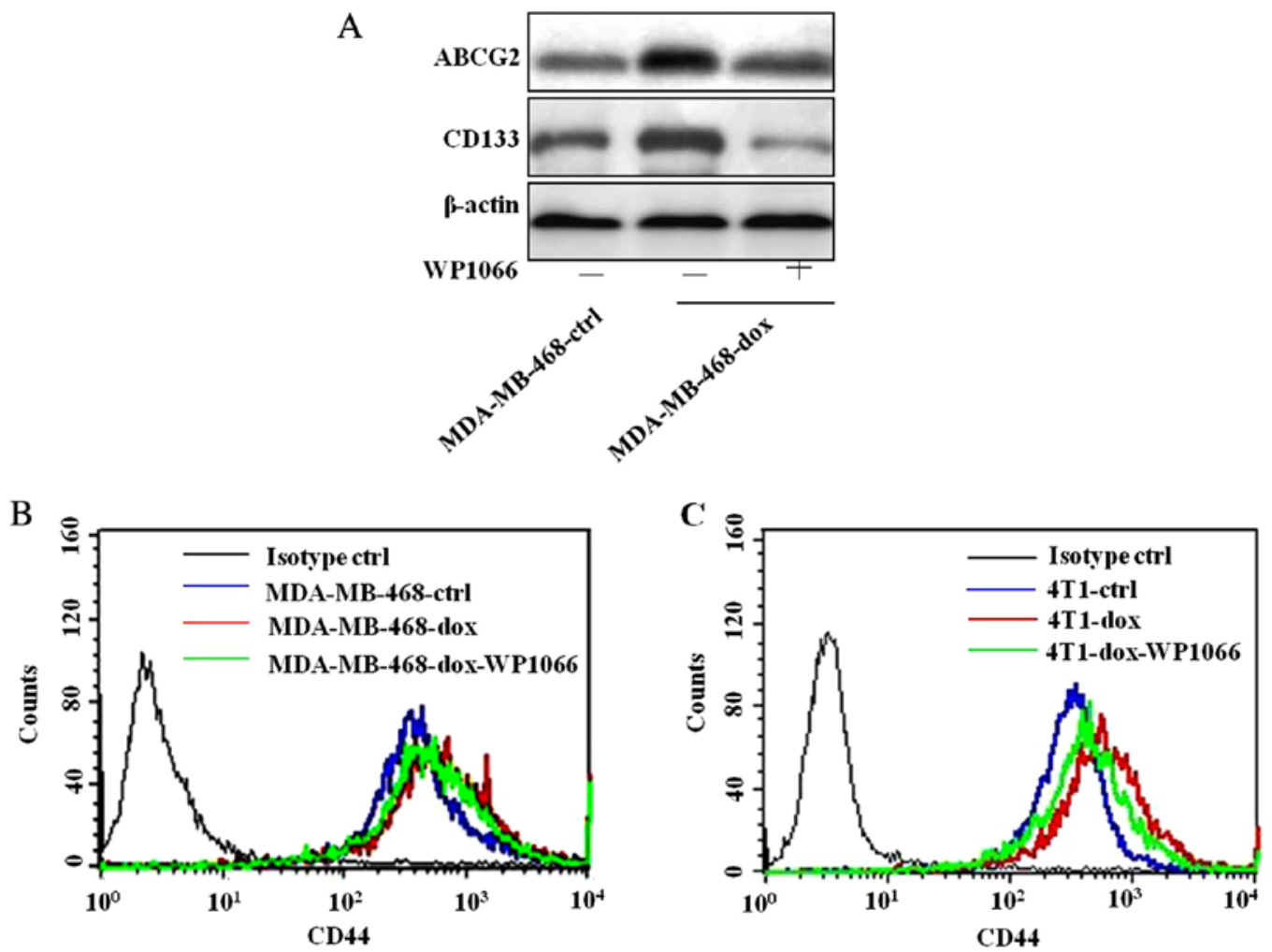

Figure 5. Inactivation of Stat 3 by WP1066 reduces cancer stem cells enriched by Dox. (A) Changes in the expression of CD133 and ABCG2 in MDA-MB-468-Dox cells with the use of WP1066 were examined by western blot analysis. (B) Changes in the expression of CD44 with the use of WP1066 in MDA-MB-468-Dox cells were detected by flow cytometry. (C) Changes in the expression of CD44 with the use of WP1066 in 4T1-Dox cells was detected by flow cytometry. The results are representative of three independent experiments. Dox, doxorubicin; ABCG2, ATP-binding cassette subfamily G member 2; ctrl, control. 


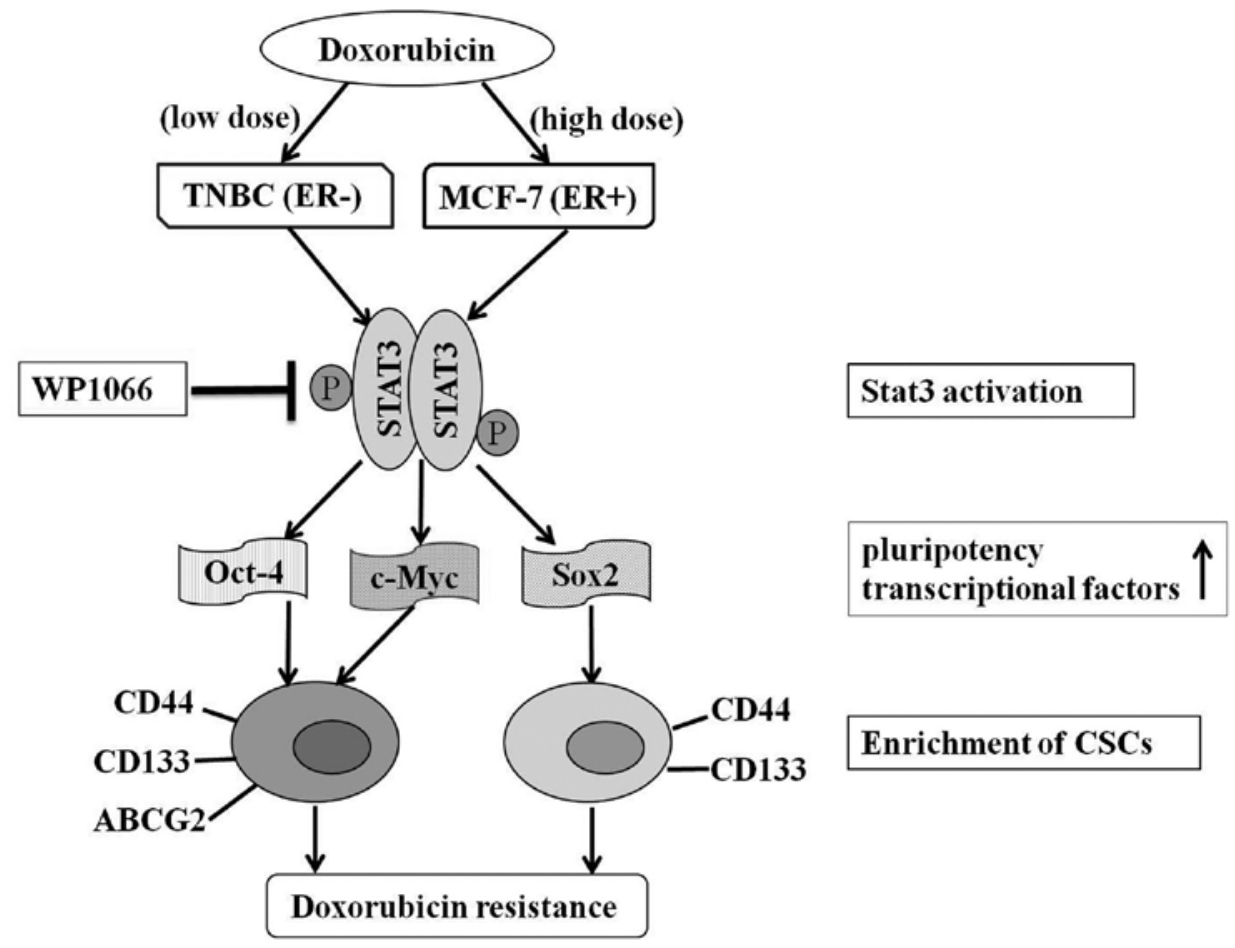

Figure 6. Hypothetic model for different pathways in the regulation of Dox-resistance through CSC enrichment in TNBCs and ER-positive MCF-7 breast cancer cells. The continuous stimulation of doxorubicin at low concentrations induced phosphorylation of Stat 3 and increased expression levels of Oct-4 and c-Myc, constituting a Stat3/Oct-4/c-Myc signaling circuit to mediate CSC enrichment and leading to the resistance of TNBC cells to Dox. Inactivation of Stat 3 may overcome the resistance to Dox through decreasing enrichment of CSCs. However, in the ER-positive MCF-7 cells, a high dose of Dox induced Dox resistance through the activation of Stat3 and the upregulation of SOX2, which differed from TNBCs. The Stat3 inhibitor WP1066 markedly decreased the expression of Oct-4 and c-Myc, resulting in the reduction of CSCs, and restored the sensitivity of TNBCs to Dox. Dox, doxorubicin; TNBC, triple-negative breast cancer; CSCs, cancer stem cells; ER, estrogen receptor; Stat3, signal transducer and activator of transcription 3; Sox2, superoxide dismutase 2; Oct-4, octamer-binding transcription factor 4; ABCG2, ATP-binding cassette subfamily G member 2.

amplifying pluripotent stem cells (44,57-59), however, the functional interaction has proven obscure. In the present study, it was found that the pluripotent transcription factors Oct-4 and c-Myc were expressed at high levels, and the phosphorylation of Stat 3 was elevated in the Dox-resistant TNBC cells. Based on the above data and previous studies, a hypothetic model was suggested for the different pathways involved in the regulation of Dox-induced CSC enrichment during the development of Dox resistance between TNBCs and ER-positive breast cancer cells (Fig. 6). The activation of Stat 3 promotes the expression of Oct- 4 and c-Myc, and further induces the enrichment of CSCs in TNBC cells. However, in the case of ER-positive MCF-7 cells, a high dose of Dox induces the resistance to Dox through the formation of CSCs mediated by activation of the Stat3/Sox 2 pathway, which differs from the regulatory pattern of Stat3 during the development of resistance of TNBCs to Dox.

The Stat3 inhibitor WP1066 has been shown to be a potent antitumor agent in the treatment of malignant glioma and acute myelogenous leukemia cells $(53,54)$. However, whether WP1066 reverses the resistance to Dox in breast cancer cells remains to be fully elucidated. In the present study, it was shown that inhibiting the activation of Stat3 with WP1066 markedly decreased the expression of pluripotent transcription factors Oct-4 and c-Myc. The data from the flow cytometry assay (Fig. 4B) and peak channel analysis further demonstrated that the inhibition of Stat 3 affected the enrichment of CSC populations in Dox-resistant TNBC cells. Under treatment with WP1066, the proportion of CD44-positive cells was markedly reduced in 4T1-Dox and MDA-MB-468-Dox cells. These data revealed that the inhibition of Stat3 led to a decrease in CSC populations and restored the sensitivity of TNBC cells to Dox. As CSCs exhibit increased drug resistance, tumorigenesis and metastasis, compared with non-CSC cancer cells, it may be worthwhile to investigate the possible differential effects of the inhibition of Stat 3 on sorted CSC and non-CSC population in future investigations.

In conclusion, the data obtained in the present study provided direct evidence that a low concentration of Dox induced the enrichment of BCSCs in TNBC cells. The activated Stat3-driven stemness mediated the resistance of TNBC cells to Dox. Compared with the classic Stat3-Sox2 pathway in ER-positive breast cancer cells, phosphorylated Stat3-Oct4 and phosphorylated Stat3-c-Myc were important in the Dox-induced enrichment of BCSCs in TNBC cells. These findings highlight the therapeutic potential of WP1066 in the restoration of Dox sensitivity against TNBC through decreasing the Stat3-inducing enrichment of CSCs.

\section{Acknowledgements}

Not applicable.

\section{Funding}

This study was supported by funds from the National Natural Science Foundation of China (grant no. 81472489) and the 
Shandong Province Science and Technology Development Program, China (grant nos. 2014GGB14403 and ZR2015HL119).

\section{Availability of data and materials}

The datasets used and/or analyzed during the current study are available from the corresponding author on reasonable request.

\section{Authors' contributions}

CCC and LHS contributed to study design, experimental investigation, data analysis and manuscript drafting; XJW, SXW and XQW participated in stem cell culture and characterization; SRL, YFW and CCC conducted flow cytometry assays and data analysis; ZL and CCC performed experiments analyzing the phosphorylation and expression of transcription factors; LHS, LHW and YD contributed to the conception, analysis and interpretation of data; ZL, LHW and YD wrote, reviewed and edited the manuscript. All authors have read and approved the final manuscript.

\section{Ethics approval and consent to participate}

Not applicable.

\section{Consent for publication}

Not applicable.

\section{Competing interests}

The authors declare that they have no competing interests.

\section{References}

1. Guerriero E, Sorice A, Capone F, Storti G, Colonna G, Ciliberto G and Costantini S: Combining doxorubicin with a phenolic extract from flaxseed oil: Evaluation of the effect on two breast cancer cell lines. Int J Oncol 50: 468-476, 2017.

2. Xue JP, Wang G, Zhao ZB, Wang Q and Shi Y: Synergistic cytotoxic effect of genistein and doxorubicin on drug-resistant human breas cancer MCF-7/Adr cells. Oncol Rep 32: 1647-1653, 2014.

3. Kim SY, Kang JW, Song X, Kim BK, Yoo YD, Kwon YT and Lee YJ: Role of the IL-6-JAK1-STAT3-Oct-4 pathway in the conversion of non-stem cancer cells into cancer stem-like cells. Cell Signal 25: 961-969, 2013.

4. Thiagarajan PS, Hitomi M, Hale JS, Alvarado AG, Otvos B, Sinyuk M, Stoltz K, Wiechert A, Mulkearns-Hubert E, Jarrar A, et al: Development of a fluorescent reporter system to delineate cancer stem cells in triple-negative breast cancer. Stem Cells 33: 2114-2125, 2015.

5. Calcagno AM,Salcido CD, Gillet JP, Wu CP, Fostel JM, Mumau MD, Gottesman MM, Varticovski L and Ambudkar SV: Prolonged drug selection of breast cancer cells and enrichment of cancer stem cell characteristics. J Natl Cancer Inst 102: 1637-1652, 2010.

6. Wang H, Agarwal P, Zhao S, Yu J, Lu X and He X: Combined cancer therapy with hyaluronan-decorated fullerene-silica multifunctional nanoparticles to target cancer stem-like cells. Biomaterials 97: 62-73, 2016.

7. Zhu T, Li LL, Xiao GF, Luo QZ, Liu QZ, Yao KT and Xiao GH: Berberine Increases Doxorubicin Sensitivity by Suppressing STAT3 in Lung Cancer. Am J Chin Med 43: 1487-1502, 2015.

8. Rueff J and Rodrigues AS: Cancer Drug Resistance: A Brief Overview from a Genetic Viewpoint. Methods Mol Biol 1395: 1-18, 2016.

9. Moitra K, Lou H and Dean M: Multidrug efflux pumps and cancer stem cells: Insights into multidrug resistance and therapeutic development. Clin Pharmacol Ther 89: 491-502, 2011.
10. Sun FF, Hu YH, Xiong LP, Tu XY, Zhao JH, Chen SS, Song J and Ye XQ: Enhanced expression of stem cell markers and drug resistance in sphere-forming non-small cell lung cancer cells. Int J Clin Exp Pathol 8: 6287-6300, 2015.

11. Karthik GM, Ma R, Lövrot J, Kis LL, Lindh C, Blomquist L, Fredriksson I, Bergh J and Hartman J: mTOR inhibitors counteract tamoxifen-induced activation of breast cancer stem cells. Cancer Lett 367: 76-87, 2015.

12. Qiao S, Zhao Y, Geng S, Li Y, Hou X, Liu Y, Lin FH, Yao L and Tian W: A novel double-targeted nondrug delivery system for targeting cancer stem cells. Int J Nanomedicine 11: 6667-6678, 2016.

13. Ma S, Lee TK, Zheng BJ, Chan KW and Guan XY: CD133+ HCC cancer stem cells confer chemoresistance by preferential expression of the Akt/PKB survival pathway. Oncogene 27: 1749-1758, 2008

14. Chen X, Lingala S, Khoobyari S, Nolta J, Zern MA and Wu J: Epithelial mesenchymal transition and hedgehog signaling activation are associated with chemoresistance and invasion of hepatoma subpopulations. J Hepatol 55: 838-845, 2011.

15. Gopalan A, Yu W, Sanders BG and Kline K: Eliminating drug resistant breast cancer stem-like cells with combination of simvastatin and gamma-tocotrienol. Cancer Lett 328: 285-296, 2013.

16. Williams KE, Bundred NJ, Landberg G, Clarke RB and Farnie G: Focal adhesion kinase and Wnt signaling regulate human ductal carcinoma in situ stem cell activity and response to radiotherapy. Stem Cells 33: 327-341, 2015.

17. Ma L, Liu T, Jin Y, Wei J, Yang Y and Zhang H: ABCG2 is required for self-renewal and chemoresistance of $\mathrm{CD} 133$-positive human colorectal cancer cells. Tumour Biol 37: 12889-12896, 2016.

18. Zhao D, Pan C, Sun J, Gilbert C, Drews-Elger K, Azzam DJ, Picon-Ruiz M, Kim M, Ullmer W, El-Ashry D, et al: VEGF drives cancer-initiating stem cells through VEGFR-2/Stat3 signaling to upregulate Myc and Sox2. Oncogene 34: 3107-3119, 2015.

19. Sainz B Jr and Heeschen C: Standing out from the crowd: Cancer stem cells in hepatocellular carcinoma. Cancer Cell 23: 431-433, 2013.

20. Yu F, Yao H, Zhu P, Zhang X, Pan Q, Gong C, Huang Y, Hu X, Su F, Lieberman J, et al: let-7 regulates self renewal and tumorigenicity of breast cancer cells. Cell 131: 1109-1123, 2007.

21. Bloushtain-Qimron N, Yao J, Snyder EL, Shipitsin M, Campbell LL, Mani SA, Hu M, Chen H, Ustyansky V, Antosiewicz JE, et al: Cell type-specific DNA methylation patterns in the human breast. Proc Natl Acad Sci USA 105: 14076-14081, 2008.

22. Li X, Lewis MT, Huang J, Gutierrez C, Osborne CK, Wu MF, Hilsenbeck SG, Pavlick A, Zhang X, Chamness GC, et al: Intrinsic resistance of tumorigenic breast cancer cells to chemotherapy. J Natl Cancer Inst 100: 672-679, 2008.

23. Kim RJ, Kim SR, Roh KJ, Park SB, Park JR, Kang KS, Kong G, Tang B, Yang YA, Kohn EA, et al: Ras activation contributes to the maintenance and expansion of Sca-1pos cells in a mouse model of breast cancer. Cancer Lett 287: 172-181, 2010.

24. Lu CS, Shieh GS, Wang CT, Su BH, Su YC, Chen YC, Su WC, Wu P, Yang WH, Shiau AL, et al: Chemotherapeutics-induced Oct 4 expression contributes to drug resistance and tumor recurrence in bladder cancer. Oncotarget 8: 30844-30858, 2017.

25. Kinugasa Y, Matsui T and Takakura N: CD44 expressed on cancer-associated fibroblasts is a functional molecule supporting the stemness and drug resistance of malignant cancer cells in the tumor microenvironment. Stem Cells 32: 145-156, 2014.

26. Hu T, Liu S, Breiter DR, Wang F, Tang Y and Sun S: Octamer 4 small interfering RNA results in cancer stem cell-like cell apoptosis. Cancer Res 68: 6533-6540, 2008.

27. Ham SL, Joshi R, Luker GD and Tavana H: Engineered Breast Cancer Cell Spheroids Reproduce Biologic Properties of Solid Tumors. Adv Healthc Mater 5: 2788-2798, 2016.

28. Han YK, Lee JH, Park GY, Chun SH, Han JY, Kim SD, Lee J, Lee CW, Yang K and Lee CG: A possible usage of a CDK4 inhibitor for breast cancer stem cell-targeted therapy. Biochem Biophys Res Commun 430: 1329-1333, 2013.

29. Blacking TM, Waterfall $M$ and Argyle DJ: CD44 is associated with proliferation, rather than a specific cancer stem cell population, in cultured canine cancer cells. Vet Immunol Immunopathol 141: 46-57, 2011.

30. Fang XJ, Jiang H, Zhu YQ, Zhang LY, Fan QH and Tian Y: Doxorubicin induces drug resistance and expression of the novel CD44st via NF- $\mathrm{BB}$ in human breast cancer MCF-7 cells. Oncol Rep 31: 2735-2742, 2014. 
31. Yae T, Tsuchihashi K, Ishimoto T, Motohara T, Yoshikawa M, Yoshida GJ, Wada T, Masuko T, Mogushi K, Tanaka H, et al: Alternative splicing of CD44 mRNA by ESRP1 enhances lung colonization of metastatic cancer cell. Nat Commun 3: 883, 2012.

32. Croker AK, Goodale D, Chu J, Postenka C, Hedley BD, Hess DA and Allan AL: High aldehyde dehydrogenase and expression of cancer stem cell markers selects for breast cancer cells with enhanced malignant and metastatic ability. J Cell Mol Med 13: 2236-2252, 2009.

33. Dalerba P, Dylla SJ, Park IK, Liu R, Wang X, Cho RW, Hoey T, Gurney A, Huang EH, Simeone DM, et al: Phenotypic characterization of human colorectal cancer stem cells. Proc Natl Acad Sci USA 104: 10158-10163, 2007.

34. Zhang G, Wang Z, Luo W, Jiao H, Wu J and Jiang C: Expression of potential cancer stem cell marker ABCG2 is associated with malignant behaviors of hepatocellular carcinoma. Gastroenterol Res Pract 2013: 782581, 2013.

35. Mi YJ, Liang YJ, Huang HB, Zhao HY, Wu CP, Wang F, Tao LY, Zhang CZ, Dai CL, Tiwari AK, et al: Apatinib (YN968D1) reverses multidrug resistance by inhibiting the efflux function of multiple ATP-binding cassette transporters. Cancer Res 70: 7981-7991, 2010.

36. Dai Y, Liu S, Zhang WQ, Yang YL, Hang P, Wang H, Cheng L, Hsu PC, Wang YC, Xu Z, et al: YAP1 regulates ABCG2 and cancer cell side population in human lung cancer cells. Oncotarget 8: 4096-4109, 2017.

37. Zhao W, Luo Y, Li B and Zhang T: Tumorigenic lung tumorospheres exhibit stem-like features with significantly increased expression of CD133 and ABCG2. Mol Med Rep 14: 2598-2606, 2016.

38. Selbo PK, Weyergang A, Eng MS, Bostad M, Mælandsmo GM, Høgset A and Berg K: Strongly amphiphilic photosensitizers are not substrates of the cancer stem cell marker ABCG2 and provides specific and efficient light-triggered drug delivery of an EGFR-targeted cytotoxic drug. J Control Release 159: 197-203, 2012.

39. Grosse-Gehling P, Fargeas CA, Dittfeld C, Garbe Y, Alison MR, Corbeil D and Kunz-Schughart LA: CD133 as a biomarker for putative cancer stem cells in solid tumours: Limitations, problems and challenges. J Pathol 229: 355-378, 2013.

40. Feng BH, Liu AG, Gu WG, Deng L, Cheng XG, Tong TJ and Zhang HZ: CD133+ subpopulation of the HT1080 human fibrosarcoma cell line exhibits cancer stem-like characteristics. Oncol Rep 30: 815-823, 2013.

41. Suvà ML, Riggi N, Stehle JC, Baumer K, Tercier S, Joseph JM, Suvà $\mathrm{D}$, Clément $\mathrm{V}$, Provero $\mathrm{P}$, Cironi $\mathrm{L}$, et al: Identification of cancer stem cells in Ewing's sarcoma. Cancer Res 69: 1776-1781, 2009.

42. Wang XQ, Ongkeko WM, Chen L, Yang ZF, Lu P, Chen KK, Lopez JP, Poon RT and Fan ST: Octamer 4 (Oct4) mediates chemotherapeutic drug resistance in liver cancer cells through a potential Oct4-AKT-ATP-binding cassette G2 pathway. Hepatology 52: 528-539, 2010.

43. Loh $\mathrm{YH}, \mathrm{Ng} \mathrm{JH}$ and $\mathrm{Ng} \mathrm{HH}$ : Molecular framework underlying pluripotency. Cell Cycle 7: 885-891, 2008.

44. Hall J, Guo G, Wray J, Eyres I, Nichols J, Grotewold L, Morfopoulou S, Humphreys P, Mansfield W, Walker R, et al: Oct4 and LIF/Stat3 additively induce Krüppel factors to sustain embryonic stem cell self-renewal. Cell Stem Cell 5: 597-609, 2009.
45. Li QQ, Xie YK, Wu Y, Li LL, Liu Y, Miao XB, Liu QZ, Yao KT and Xiao GH: Sulforaphane inhibits cancer stem-like cell properties and cisplatin resistance through miR-214-mediated downregulation of c-MYC in non-small cell lung cancer. Oncotarget 8: 12067-12080, 2017.

46. Kidder BL, Yang J and Palmer S: Stat 3 and c-Myc genome-wide promoter occupancy in embryonic stem cells. PLoS One 3: e3932, 2008.

47. Meyer N and Penn LZ: Reflecting on 25 years with MYC. Nat Rev Cancer 8: 976-990, 2008.

48. Myung SJ, Yoon JH and Yu SJ: STAT3 \& Cytochrome P450 2C9: A novel signaling pathway in liver cancer stem cells. Biomed Pharmacother 66: 612-616, 2012.

49. Gariboldi MB, Ravizza R, Molteni R, Osella D, Gabano E and Monti E: Inhibition of Stat3 increases doxorubicin sensitivity in a human metastatic breast cancer cell line. Cancer Lett 258 181-188, 2007.

50. Zhou J, Wulfkuhle J, Zhang H, Gu P, Yang Y, Deng J, Margolick JB, Liotta LA, Petricoin E III and Zhang Y: Activation of the PTEN/mTOR/STAT3 pathway in breast cancer stem-like cells is required for viability and maintenance. Proc Natl Acad Sci USA 104: 16158-16163, 2007.

51. Zhou X, Ren Y, Liu A, Jin R, Jiang Q, Huang Y, Kong L, Wang X and Zhang L: WP1066 sensitizes oral squamous cell carcinoma cells to cisplatin by targeting STAT3/miR-21 axis. Sci Rep 4: 7461,2014

52. Yu J, Yuan X,Liu Y,Zhang K, Wang J,Zhang H and Liu F: Delayed administration of WP1066, an STAT3 inhibitor, ameliorates radiation-induced lung injury in mice. Hai 194: 67-74, 2016.

53. Hussain SF, Kong LY, Jordan J, Conrad C, Madden T, Fokt I, Priebe $\mathrm{W}$ and Heimberger AB: A novel small molecule inhibitor of signal transducers and activators of transcription 3 reverses immune tolerance in malignant glioma patients. Cancer Res 67: 9630-9636, 2007.

54. Kong LY, Wei J, Sharma AK, Barr J, Abou-Ghazal MK, Fokt I, Weinberg J, Rao G, Grimm E, Priebe W, et al: A novel phosphorylated STAT3 inhibitor enhances T cell cytotoxicity against melanoma through inhibition of regulatory $\mathrm{T}$ cells. Cancer Immunol Immunother 58: 1023-1032, 2009.

55. Gao W, McCormick J, Connolly M, Balogh E, Veale DJ and Fearon U: Hypoxia and STAT3 signalling interactions regulate pro-inflammatory pathways in rheumatoid arthritis. Ann Rheum Dis 74: 1275-1283, 2015

56. Wang Y, Chen L, Bao Z, Li S, You G, Yan W, Shi Z, Liu Y, Yang $\mathrm{P}$, Zhang W, et al: Inhibition of STAT3 reverses alkylator resistance through modulation of the AKT and $\beta$-catenin signaling pathways. Oncol Rep 26: 1173-1180, 2011.

57. Kim JH, Lee SC, Ro J, Kang HS, Kim HS and Yoon S: Jnk signaling pathway-mediated regulation of Stat 3 activation is linked to the development of doxorubicin resistance in cancer cell lines. Biochem Pharmacol 79: 373-380, 2010.

58. Iliopoulos D, Hirsch HA, Wang G and Struhl K: Inducible formation of breast cancer stem cells and their dynamic equilibrium with non-stem cancer cells via IL6 secretion. Proc Natl Acad Sci USA 108: 1397-1402, 2011.

59. Niwa H, Burdon T, Chambers I and Smith A: Self-renewal of pluripotent embryonic stem cells is mediated via activation of STAT3. Genes Dev 12: 2048-2060, 1998. 